\title{
Wharton's Jelly Mesenchymal Stem Cells: Differentiation Capacity Showing its Role in Bone Tissue Engineering
}

\author{
Rizal Rizal1 ${ }^{*}$, Rahimi Syaidah², Evelyn Evelyn³ ${ }^{3}$ Alif Muhammad Hafizh³, Josh Frederich ${ }^{3}$ \\ ${ }^{1}$ Biomedical Engineering Study Program, Department of Electrical Engineering, Faculty of Engineering, \\ Universitas Indonesia, Kampus UI Depok, Depok 16424, Indonesia \\ ${ }^{2}$ Department of Histology, Faculty of Medicine, Universitas Indonesia, Kampus UI Depok, Depok 16424, \\ Indonesia \\ ${ }^{3}$ Undergraduate program in Biomedical Engineering, Department of Electrical Engineering, Faculty of \\ Engineering, Universitas Indonesia, Kampus UI Depok, Depok 16424, Indonesia
}

\begin{abstract}
Wharton's jelly mesenchymal stem cells (WJ-MSCs) is one of the best sources of mesenchymal stem cells (MSCs) that suggest both embryonic and adult stem cell characteristics. Before being applied in clinical application, the isolated MSCs should be tested to assess their quality, including differentiation capacity, phenotype characterization, and morphological appearance. This research aims to quantify the differentiation capacity of WJ-MSCs isolated using explant method. The WJ-MSCs cells were grown out from Wharton's jelly tissue and the isolated cells adhered in T25 plastic flask. The isolated cells expressed high amount of MSC surface marker which are CD105 (99.97 $\pm 0.06 \%)$, CD73 (99.97 $\pm 0.06 \%)$, and CD90 (99.12 $\pm 0.25 \%)$. The cells can be differentiated into adipocytes, chondrocytes, and osteocytes. The quantification showed that the amount of mineralization in osteoblastogenesis, production of lipid droplet in adipogenic differentiation, and production of glycosaminoglycan in chondrogenesis were noticeably higher in differentiated cells than non-differentiated cells. In conclusion, the isolated cells fulfill the minimum criteria of MSCs that can be used in research or clinical application. The great differentiation capacity of the cells into osteocytes and chondrocytes indicate that the cells are suitable in bone tissue engineering application, both for research and clinical application.
\end{abstract}

Keywords: Adipocytes; Chondrocytes; Differentiation capacity; Osteocytes; WJ-MSCs

\section{Introduction}

Present materials, which are incorporated with osteoinductive properties, are continually developed for bone tissue engineering utilization to generate osteogenesis at the implant site. Graphene, which is generally a monoatomic two-dimensional sheet-like material with sp2-hybridized carbon atoms arranged in a hexagonal or honeycomb-like structure, and its thickness identical to an atom diameter, is one example of these materials with documented pro-osteogenic effects (Hermenean et al., 2016; Kusrini et al., 2019). However, it possesses a challenge to produce the materials (Supriadi et al., 2017). Another example is mesoporous silica nanoparticles (MSN). Osteogenic agents are added to the MSNs augment the bone regeneration process (Narayan et al., 2018). Porous materials are widely used as adsorbents, catalysts, and catalyst support due to their large surface area and pore volume characteristics (Wilson and Mahmud, 2015). However, to increase bone

*Corresponding author's email: rizal@eng.ui.ac.id, Tel.: +62-85255455460

doi: 10.14716/ijtech.v11i5.4309 
healing recovery, those materials should be combined with multipotent cells that have the properties of high self-proliferation and differentiation into bone-related cells.

Multipotent cells with high capacity of self-proliferation that can be derived from almost all parts of the body, including neonatal byproducts, bone marrow, adipose tissue, and dental tissue, are called Mesenchymal stem cells (MSCs) (Hass et al., 2011; Shivakumar et al., 2019). The MSCs hold a promising potential application for regenerative disease and immunomodulation (Abdallah and Kassem, 2008). These have been approved for the treatment of various diseases such as Crohn-related enterocutaneous fistular disease and graft versus host disease (Galipeau and Sensébé, 2018). The MSCs have also been explored to address several immunological disease (Ghannam et al., 2010), bone and cartilage defects (Krampera et al., 2006), neurological degeneration (Karussis et al., 2010), and cardiovascular diseases (Ranganath et al., 2012).

Several findings suggested that birth byproducts have better proliferation and differentiation capacity (Anzalone et al., 2010; Hass et al., 2011). The MSCs can be isolated from various birth byproducts including amniotic membrane and fluid (Wolbank et al., 2007; Utama, 2018), umbilical cord (Van Pham et al., 2016), Wharton's jelly tissue (Widowati et al., 2019), and umbilical cord blood (Bieback and Netsch, 2016). Isolated MSCs from neonatal-derived tissues also have both embryonic and adult stem cell characteristics (Arutyunyan et al., 2016).

Wharton's jelly tissues are part of the umbilical cord that are considered as one of the finest sources of MSCs. The advantages of using these tissues are ethical consideration, their availability, and non-invasive isolation procedure (Hass et al., 2011). Before their clinical application, there are several quality controls to examine the quality of WJ-MSCs. The minimal criteria that have been accepted in both industrial and basic research application has been published by the International Society for Cellular Therapy (ISCT) (Dominici et al., 2006). There are three minimal criteria for MSCs: adherence to plastic, positive ( $>95 \%)$ for CD105, CD73, and CD90, and can be differentiated into osteocytes, chondrocytes, and adipocytes.

The aspects that may affect the differentiation capacity of MSCs are tissue origin, isolation method, culture condition, and cells passage (Ahern et al., 2011; Hass et al., 2011; Nepali et al., 2018; Rizal et al., 2019). They also can be trans-differentiated into ectodermal lineage and endodermal lineage cells, including $\beta$-pancreas (Ullah et al., 2019), neuronal cells (Cortés-Medina et al., 2019), and cardiomyocytes (Arslan et al., 2018). This differentiation capacity makes stem cells prospective for transplantation, thus having the ability to repair many organ disfunctions. In addition, MSCs are able to migrate and differentiate in the area of injury using the ability called homing capacity (Lin et al., 2017; Ullah et al., 2020). These benefits make the research of exploring the potential of MSCs very popular (Zakrzewski et al., 2019).

Differentiation capacity into osteocytes is one of the strengths of WJ-MSCs that can be applied in bone tissue engineering (Ansari et al., 2018). The WJ-MSCs reveal all characteristics of functional osteocytes/osteoblasts due to its osteogenic gene expression, the ability to adhere in scaffold, and expression of extracellular matrix mineralization (Todeschi et al., 2015). They have been successfully transplanted into patients to treat osteonecrosis and exhibited improvement in the joint function and also relieved the pain (Cai et al., 2014).

Compared with bone marrow mesenchymal stem cells (BM-MSCs), the application of WJ-MSCs in bone tissue engineering has several advantages. The isolation procedure of WJMSCs are non-invasive because it comes from byproduct waste pain (Wang et al., 2016). The WJ-MSCs also have low immunogenicity that enable us to use these cells in both autologous 
and allogenic transplantation. When transplanted into human body, WJ-MSCs are protected against lysis by NK cells because these cells express low quantity of primary major histocompatibility class I (MHCI) and class II (MHCII) proteins (Kalaszczynska and Ferdyn, 2015). There are no teratoma formation after transplantation of WJ-MSCs in mice, as well as the patients (Ding, 2015).

Present study strives to quantify the differentiation capacity of MSCs into three different mesodermal cells lineage: adipocytes, chondrocytes, and osteocytes. Because of the heterogeneity of stem cells, the quantification of the quality of stem cells become an important criterion in the quality check of MSCs before being transplanted into human body, and in future all the minimal criteria of stem cells should be measurable to ease the quality control check of MSCs.

\section{Methods}

\subsection{WJ-MSCs Isolation}

The explant method was used to isolate the cells, as described in the previous study (Rizal et al., 2018; Rizal et al., 2019). Briefly, phosphate-buffered saline (PBS) 1× was used to remove blood cells from the tissue, which was then placed into a transport medium containing PBS $1 \times$ (Gibco, Invitrogen, USA), $1 \%$ amphotericin- $\beta(\mathrm{v} / \mathrm{v}$ ) (Gibco, Invitrogen, USA), $1 \%$ (v/v) penicillin-streptomycin (Gibco, Invitrogen, USA), and $20 \mu \mathrm{g} / \mathrm{ml}$ gentamicin (Gibco, Invitrogen, USA). Next, blood vessels (arterial and venous) were longitudinally separated from the tissue and the tissue was then cut into 1-2 $\mathrm{cm}^{3}$ explant fragments while washing with sterile PBS. All the explant fragments were next placed on $60 \mathrm{~mm}$ tissue culture plates (MCD110090) and supplemented with complete growth medium containing MEM- $\alpha$ (Gibco, Invitrogen, Canada), $10 \%(\mathrm{v} / \mathrm{v}$ ) fetal bovine serum (Gibco, Invitrogen Corporation, Grand Island, NY, USA), 1\% (v/v) pen-strep (Gibco, Invitrogen, USA), 1\% (v/v) amphotericin- $\beta$ (Gibco Invitrogen, USA), and $20 \mathrm{mg} / \mathrm{ml}$ gentamicin (Gibco Invitrogen, USA). The fragment was incubated at $5 \% \mathrm{CO}_{2}, 37^{\circ} \mathrm{C}$. Every 3 days, the medium must be replaced with fresh growth medium. After the cells moved out from the tissue, these cells were cultured and expanded in WJ-MSCs-complete growth medium.

\subsection{WJ-MSCs Characterization}

Flow cytometry was used to analyze WJ-MSCs surface markers using Macsquant, Analyzer 10. Briefly, trypsin-EDTA was used to dissociate WJ-MSCs at $80 \%$ confluence and centrifuged at $5000 \mathrm{rpm}$ for 5 minutes. The pellet was then resuspended with PBS $1 \times$, FBS, and cells were counted with a hemocytometer. The isolated cells were stained with appropriate positive surface antibodies as follows: CD90-FITC, CD105-PerCP-Cy5, CD73APC, CD44-PE, and negative surface antibodies of CD34-PE, CD116-PE, CD19-PE, CD45-PE, HLA-DR-PE, according to manufacturer's protocol (BD stem flowKit, Becton, USA). Isotype controls were used as background staining (Widowati et al., 2019).

\subsection{Quantification of WJ-MSCs Multilineage Differentiation}

Osteogenic differentiation quantification: Osteogenic differentiation was conducted using StemPro Osteogenesis Differentiation Kit (Gibco A10072-01) under manufacturer protocol. A total of $5 \times 10^{3}$ cells WJ-MSCs were seeded in 24 well plates (Nunc, 72296-18) and were exposed by StemPro Osteogenesis Differentiation medium for 3 weeks. Calcium deposits were stained using Alizarin Red S (Sigma, A5533). Alizarin Red S was extracted from samples by addition of $10 \%$ cetyl-pyridinium chloride in $10 \mathrm{mM}$ sodium phosphate (pH 7.0 [wt/vol]) to wells and incubated for 60 minutes. Mineral content was quantitated by use of a plate reader spectrophotometer (Multiscan Go Thermoscientific, Massachusetts, USA) at $562 \mathrm{~nm}$ (Ahern et al., 2011). 
Chondrogenic differentiation quantification: A total of $5 \times 10^{3}$ cells were plated in four well plates (Nunc, 176740) and were exposed with StemPro Chondrogenesis Differentiation Kit (Gibco, A10071-01) for 3 weeks. Chondrocytes were stained using Alcian Blue (Sigma, A5268) (Widowati et al., 2019). Alcian Blue was extracted from the cells using $6 \mathrm{M}$ guanidine $\mathrm{HCl}$ for 2 hours at room temperature and the absorbance was measured at $650 \mathrm{~nm}$ using a spectrophotometer (Multiscan Go Thermoscientific, USA).

Adipogenic differentiation quantification: Cells were plated at density $1.1 \times 10^{4} \mathrm{cell} / \mathrm{cm}^{2}$ in four well plates (Nunc, Thermo Scientific, USA) and incubated around 2 days in a growth medium at $37^{\circ} \mathrm{C}, 5 \% \mathrm{CO}_{2}$. The cells were then exposed to StemPro Adipogenesis Differentiation Medium (Gibco, Invitrogen, USA) for approximately 21 days. Then, 4\% paraformaldehyde was used to fix cells around 30 minutes at room temperature and stained with Oil Red O (Sigma, Missouri, USA) to examine intracellular lipid droplets (Ahern et al., 2011). Lipid droplets were extracted with $200 \mu \mathrm{l}$ of $100 \%$ isopropanol (Merck, Germany) for 15 minutes and the absorbance was measured using plate reader spectrophotometer (Multiscan Go Thermoscientific, Massachusetts, USA) at 540nm (Nepali et al., 2018).

\section{Results and Discussion}

\subsection{WJ-MSC Isolation and Characterization}

WJ-MSCs were successfully isolated from Wharton's jelly tissues and can adhere in plastic T25 flask. The cells moved out of the Wharton's jelly tissue after 2 weeks of culture. The isolated cells were maintained until Passage 9. The cells have typical stem cell morphological appearance, that is, they are spindle-shaped and fibroblast-like cells (Kim et al., 2013).

By using flow cytometry, the surface markers of stem cells were then analyzed, and the result were revealed in Table 1 . The expression of three main surface markers for MSCs were highly expressed $(99.12 \pm 0.25$ for CD90; $99.97 \pm 0.06$ for CD105; $95.9 \pm 0.65$ for CD73), while the expression of the negative MSCs markers, which were CD34-, CD45-, CD11 b', $\mathrm{CD}^{-} 4^{-}, \mathrm{CD}^{-} 9^{-}, \mathrm{CD}^{2} \mathrm{a}^{-}$, and HLA-DR-${ }^{-}$, were not expressed in the isolated cells.

Table 1 The expression of surface markers of WJ-MSCs in Passage 5

\begin{tabular}{cc}
\hline Surface markers & $\begin{array}{c}\text { Percentage of } \\
\text { expression }\end{array}$ \\
\hline CD90 & $99.12 \pm 0.25$ \\
CD44 & $89.34 \pm 1.08$ \\
CD105 & $99.97 \pm 0.06$ \\
CD73 & $95.9 \pm 0.65$ \\
Negative lineages & $0.00 \pm 0.00$ \\
\hline
\end{tabular}

Isolated WJ-MSCs in Passage 5 revealed high quality of MSCs that fulfill the minimal criteria of stem cells developed by ISCT (Dominici et al., 2006). The MSCs are known to have positive expression of CD73, CD9, and CD105, and have negative expression of cluster differentiation (CD45, CD34, and HLA-DR) and hematopoietic surface markers (Baer et al., 2012). The CD73, CD90, and CD105 markers are likely to have function in cell cycle, proliferation, survival, migration, adhesion, and differentiation (Pierelli et al., 2001; Zhang, 2010; Moraes et al., 2016). The expression of this surface markers is affected by several factors such as passage and culture condition (Wagner et al., 2006; Wagner et al., 2008). The data reveals that the isolation technique and culture condition used in this research generate high quality of stem cells. 


\subsection{Differentiation Capacity}

The differentiation capacity of WJ-MSCs into mesodermal cells, including adipocytes, osteocytes, and chondrocytes, has been proven. The differentiation ability into adipocytes was examined using Oil Red 0 stain to detect oil droplet produced by adipocytes, as shown in Figure 1. The calcium deposits were detected through Alizarin Red S staining. The chondrocyte differentiation was shown using Alcian Blue stain, as depicted in Figure 1.

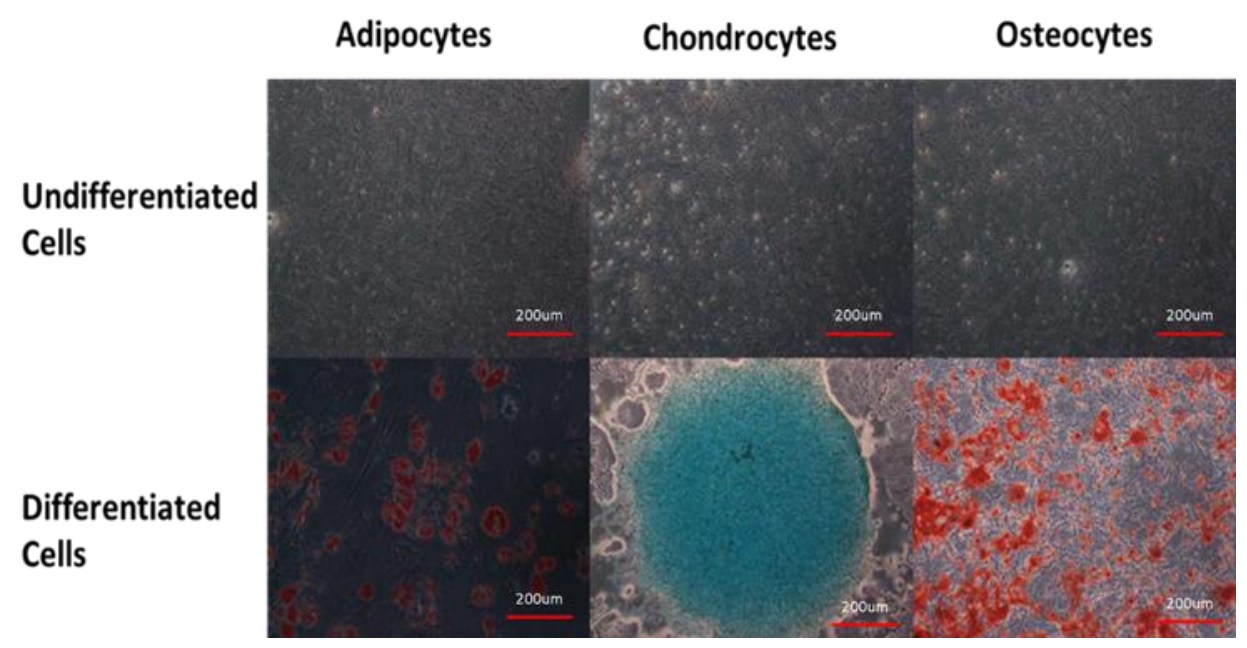

Figure 1 Staining of differentiated and undifferentiated cells of Isolated WJ-MSCs

The result exhibited that the isolated WJ-MSCs can be differentiated into adipocyte, chondrocyte, and osteocyte cells. Differentiation capacity of WJ-MSCs into adipocytes, chondrocytes, and osteocytes has been reported by some researchers (Widowati et al., 2019).

Differentiation capacity of MSCs into three different lineages was affected by various factors. The sources of the cells, as reported by Ahern et al. (2011), have a significant effect on the differentiation ability of MSCs. The differentiation into adipocytes of adipose-derived MSCs (AD-MSCs) was significantly higher when compared with BM-MSCs. In contrast, osteogenic differentiation was higher in BM-MSCs (Ahern et al., 2011). Another factor affecting differentiation capacity is passage. Rizal et al. (2019) also reported that the adipogenic differentiation was significantly higher in early passage than in higher passage.

\subsection{Quantification of Differentiation Capacity}

The results of differentiation capacity quantification of isolated WJ-MSCs are exhibited in Figure 2. Lipid quantification reveals that the amounts of oil droplets were significantly higher in differentiated cells. The lipid content was $1.25 \pm 0.04$ time higher in differentiated cells when compare with undifferentiated cells. Compared with the cells that did not differentiate, the amounts of mineralization happening in the osteoblastogenesis was $3.49 \pm 0.05$ times higher in differentiated cells. Finally, the total of GAG production in chondrogenesis was significantly higher in differentiated cells. The relative absorbance of differentiated cells was $2.16 \pm 0.06$.

The quantification of differentiation capacity gives us more accurate and measurable information about the stem cell quality. The quantification can be used to assess the quality of stem cells from different sources or passages. Nepali et al. (2018) examined the differentiation quality of AD-MSCs isolated from different sources of fats, and the quantification of differentiation capacity assists them to determine the best sources of MSCs. In addition, Ahern et al. (2011) examined the differentiation capacity of MSCs 
quantitatively to determine the better differentiation capacity of peripheral blood, bone marrow, and adipose tissue MSCs.

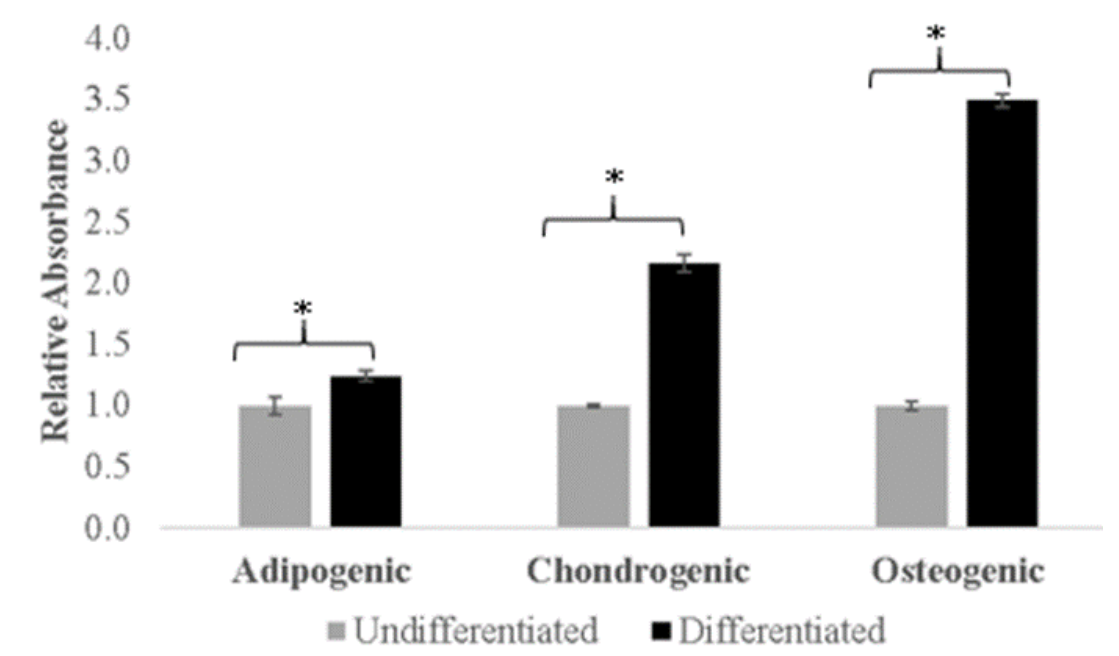

Figure 2 The quantification of undifferentiated and differentiated isolated WJ-MSCs into three different lineages

This result revealed that the differentiation capability of WJ-MSCs to osteocytes and chondrocytes is greater than its differentiation capability into adipocytes. This finding suggested that WJ-MSCs hold a great potential to be applied in bone tissue engineering. Both the capability of differentiation into osteogenesis and factors necessary for bone formation are possessed by WJ-MSC (Kosinski et al., 2020). The WJ-MSCs secrete several proteins such as VEGF-D (Obtulowicz et al., 2016; Kosinski et al., 2020), BMP-2 (La Rocca et al., 2013; Kosinski et al., 2020), IL-6, IL-1, TNF- $\alpha$ (Kyurkchiev et al., 2014; Kosinski et al., 2020), OPG, and RANKL (Zajdel et al., 2017; Kosinski et al., 2020) that hold crucial role in bone formation.

Present investigation in an Indonesian patient with an infected non-union bone fracture showed that transplantation of Umbilical cord mesenchymal stem cells (UC-MSCs), supplemented with hydroxyapatite and BMP-2, improves the bone defect healing, enabling the patient to walk without pain and postoperative complications (Dilogo et al., 2017). Other research suggested that the addition of WJ-MSCs can be seeded in bone substitute and can be differentiated in osteocytes that can be applied in clinical therapy for bone defect treatment (Kosinski et al., 2020). In osteonecrosis, an allogenic and autologous transplantation of WJ-MSCs also showed the ability to cure the disease (Cai et al., 2014). This suggested that WJ-MSCs hold a chance to be immediately applied in clinical application for bone tissue engineering.

\section{Conclusions}

The current study indicates that the WJ-MSCs, isolated through explant methods, generate high-quality stem cells that are in line with mesenchymal stem cell criteria. The isolated WJ-MSCs can be differentiated into adipocytes, chondrocytes, and adipocytes. This capacity can be quantified, producing better determination on the quality of stem cells and their role in bone tissue engineering. 


\section{Acknowledgements}

This study was supported by a grant from Universitas Indonesia, PUTI Prosiding 2020, contract no. NKB-912/UN.RST/HKP.05.00/2020.

\section{References}

Abdallah, B.M., Kassem, M., 2008. Human Mesenchymal Stem Cells: From Basic Biology to Clinical Applications. International Journal of Gene therapy, Volume 15(2), pp. 109-116

Ahern, B.J., Schaer, T.P., Terkhorn, S.P., Jackson, K.V., Mason, N.J., Hankenson, K.D., 2011. Evaluation of Equine Peripheral Blood Apheresis Product, Bone Marrow, and Adipose Tissue as Sources of Mesenchymal Stem Cells and their Differentiation Potential. American Journal of Veterinary Research, Volume 72(1), pp. 127-133

Ansari, A.S., Yazid, M.D., Sainik, N.Q.A.V., Razali, R.A., Saim, A.B., Idrus, R.B.H., 2018. Osteogenic Induction of Wharton's Jelly-Derived Mesenchymal Stem Cell for Bone Regeneration: A Systematic Review. Stem Cells International, Volume 2018(4), pp. 117

Anzalone, R., Iacono, M.L., Corrao, S., Magno, F., Loria, T., Cappello, F., Zummo, G., Farina, F., Rocca, G.L., 2010. New Emerging Potentials for Human Wharton's Jelly Mesenchymal Stem Cells: Immunological Features and Hepatocyte-like Differentiative Capacity. International Journal of Stem Cells and Development, Volume 19(4), pp. 423438

Arslan, Y.E., Galata, Y.F., Arslan, T.S., Derkus, B., 2018. Trans-differentiation of Human Adipose-Derived Mesenchymal Stem Cells into Cardiomyocyte-like Cells on Decellularized Bovine Myocardial Extracellular Matrix-based Films.Journal of Materials Science: Materials in Medicine, Volume 29(127), https://doi.org/10.1007/s10856-018-6135-4

Arutyunyan, I., Elchaninov, A., Makarov, A., Fatkhudinov, T., 2016. Umbilical Cord as Prospective Source for Mesenchymal Stem Cell-based Therapy. Stem Cells International, Volume 2016(3), pp. 1-17

Baer, P.C., Geiger, H., 2012. Adipose-Derived Mesenchymal Stromal/Stem Cells: Tissue Localization, Characterization, and Heterogeneity. Stem Cells International, Volume 2012(3), pp. 1-11

Bieback, K., Netsch, P., 2016. Isolation, Culture, and Characterization of Human Umbilical Cord Blood-Derived Mesenchymal Stromal Cells. In Mesenchymal Stem Cells, pp. 245258. Humana Press, New York

Cai, J., Wu, Z., Huang, L., Chen, J., Wu, C., Wang, S., Deng, Z., Wu, W., Luo, F., Tan, J., 2014. Cotransplantation of Bone Marrow Mononuclear Cells and Umbilical Cord Mesenchymal Stem Cells in Avascular Necrosis of the Femoral Head. In: Transplantation Proceedings, Volume 46(1), pp. 151-155

Cortés-Medina, L.V., Pasantes-Morales, H., Aguilera-Castrejon, A., Picones, A., Lara-Figueroa, C.O., Luis, E., Montesinos, J.J., Cortés-Morales, V.A., Ruiz, M.P.D.L.R., Hérnandez-Estévez, E., Bonifaz, L.C., Alvarez-Perez, M.A., Ramos-Mandujano, G., 2019. Neuronal Transdifferentiation Potential of Human Mesenchymal Stem Cells from Neonatal and Adult Sources by a Small Molecule Cocktail. Stem Cells International, Volume 2019, pp. $1-13$

Dilogo, I.H., Primaputra, M.R.A., Pawitan, J.A., Liem, I.K., 2017. Modified Masquelet Technique using Allogeneic Umbilical Cord-Derived Mesenchymal Stem Cells for Infected Non-Union Femoral Shaft Fracture with a $12 \mathrm{~cm}$ Bone Defect: A Case Report. International Journal of Surgery Case Reports, Volume 34, pp. 11-16 
Ding, D.C., Chang, Y.H., Shyu, W.C., Lin, S.Z., 2015. Human Umbilical Cord Mesenchymal Stem Cells: A New Era for Stem Cell Therapy. Cell Transplantation, Volume 24(3), pp. 339347

Dominici, M.L.B.K., Le Blanc, K., Mueller, I., Slaper-Cortenbach, I., Marini, F.C., Krause, D.S., Deans, R.J., Keating, A., Prockop, D.J., Horwitz, E.M., 2006. Minimal Criteria for Defining Multipotent Mesenchymal Stromal Cells. The International Society for Cellular Therapy Position Statement. International Journal of Cytotherapy, Volume 8(4), pp. 315-317

Galipeau, J., Sensébé, L., 2018. Mesenchymal Stromal Cells: Clinical Challenges and Therapeutic Opportunities. International Journal of Cell stem cell, Volume 22(6), pp. 824-833

Ghannam, S., Bouffi, C., Djouad, F., Jorgensen, C., Noël, D., 2010. Immunosuppression by Mesenchymal Stem Cells: Mechanisms and Clinical Applications. International Journal of Stem cell Research \& Therapy, Volume 1(2), pp. 1-7

Hass, R., Kasper, C., Böhm, S., Jacobs, R., 2011. Different Populations and Sources of Human Mesenchymal Stem Cells (MSC): A Comparison of Adult and Neonatal Tissue-Derived MSC. International Journal of Cell Communication and Signaling, Volume 9(12), pp. 114

Hermenean, A., Dinescu, S., Ionita, M., Costache, M., 2016. The Impact of Graphene Oxide on Bone Regeneration Therapies. IntechOpen, pp. 151-167

Kalaszczynska, I., Ferdyn, K., 2015. Wharton's Jelly Derived Mesenchymal Stem Cells: Future of Regenerative Medicine? Recent Findings and Clinical Significance. BioMed Research International, Volume 2015(3), pp. 1-11

Karussis, D., Karageorgiou, C., Vaknin-Dembinsky, A., Gowda-Kurkalli, B., Gomori, J.M., Kassis, I., Bulte, J.W.M., Petrou, P., Ben-Hur, T., Slavin, S., 2010. Safety and Immunological Effects of Mesenchymal Stem Cell Transplantation in Patients with Multiple Sclerosis and Amyotrophic Lateral Sclerosis. International Journal of Archives of Neurology, Volume 67(10), pp. 1187-1194

Kim, N., Cho, S.G., 2013. Clinical Applications of Mesenchymal Stem Cells. The Korean Journal of Internal Medicine, Volume 28(4), pp. 387-402

Kosinski, M., Figiel-Dabrowska, A., Lech, W., Wieprzowski, L., Strzalkowski, R., Strzemecki, D., Cheda, L., Lenart, J., Domanska-Janik, K., Sarnowska, A., 2020. Bone Defect Repair using a Bone Substitute Supported by Mesenchymal Stem Cells Derived from the Umbilical Cord. Stem Cells International, Volume 2020, pp. 1-15

Krampera, M., Pizzolo, G., Aprili, G., Franchini, M., 2006. Mesenchymal Stem Cells for Bone, Cartilage, Tendon and Skeletal Muscle Repair. International Journal of Bone, Volume 39(4), pp. 678-683

Kusrini, E., Suhrowati, A., Usman, A., Degirmenci, D.V., Khalil, M., 2019. Synthesis and Characterization of Graphite Oxide, Graphene Oxide and Reduced Graphene Oxide from Graphite Waste using Modified Hummers's Method and Zinc as Reducing Agent. International Journal of Technology, Volume 10(6), pp. 1093-1104

Kyurkchiev, D., Bochev, I., Ivanova-Todorova, E., Mourdjeva, M., Oreshkova, T., Belemezova, K., Kyurkchiev, S., 2014. Secretion of Immunoregulatory Cytokines by Mesenchymal Stem Cells. World Journal of Stem Cells, Volume 6(5), pp. 552-570

La Rocca, G., Lo Iacono, M., Corsello, T., Corrao, S., Farina, F., Anzalone, R., 2013. Human Wharton's Jelly Mesenchymal Stem Cells Maintain the Expression of Key Immunomodulatory Molecules when Subjected to Osteogenic, Adipogenic and Chondrogenic Differentiation in vitro: New Perspectives for Cellular Therapy. Current Stem Cell Research \& Therapy, Volume 8(1), pp. 100-113 
Lin, W., Xu, L., Zwingenberger, S., Gibon, E., Goodman, S.B., Li, G., 2017. Mesenchymal Stem Cells Homing to Improve Bone Healing. Journal of Orthopaedic Translation, Volume 9, pp. $19-27$

Moraes, D.A., Sibov, T.T., Pavon, L.F., Alvim, P.Q., Bonadio, R.S., Da Silva, J.R., Pic-Taylor, A., Toledo, O.A., Marti, L.C., Azevedo, R.B., Oliveira, D.M., 2016. A Reduction in CD90 (THY1) Expression Results in Increased Differentiation of Mesenchymal Stromal Cells. Stem Cell Research \& Therapy, Volume 7(1), pp. 1-14

Narayan, R., Nayak, U.Y., Raichur, A.M., Garg, S., 2018. Mesoporous Silica Nanoparticles: A Comprehensive Review on Synthesis and Recent Advances. Pharmaceutics, Volume 10(3), pp. 1-49

Nepali, S., Park, M., Lew, H., Kim, O., 2018. Comparative Analysis of Human Adipose-Derived Mesenchymal Stem Cells from Orbital and Abdominal Fat. Stem Cells International, Volume 2018(3), pp. 1-9

Obtulowicz, P., Lech, W., Strojek, L., Sarnowska, A., Domanska-Janik, K., 2016. Induction of Endothelial Phenotype from Wharton's Jelly-Derived MSCs and Comparison of their Vasoprotective and Neuroprotective Potential with Primary WJ-MSCs in CA1 Hippocampal Region ex vivo. Cell Transplantation, Volume 25(4), pp. 715-727

Pierelli, L., Bonanno, G., Rutella, S., Marone, M., Scambia, G., Leone, G., 2001. CD105 (Endoglin) Expression on Hematopoietic Stem/Progenitor Cells. Leukemia \& Lymphoma, Volume 42(6), pp. 1195-1206

Ranganath, S.H., Levy, O., Inamdar, M.S., Karp, J.M., 2012. Harnessing the Mesenchymal Stem Cell Secretome for the Treatment of Cardiovascular Disease. International Journal of Cell Stem Cell, Volume 10(3), pp. 244-258

Rizal, R., Kerans, F.F., Hermantara, R., Herningtyas, E.H., 2018. Isolation, Characterization, Proliferation, Differentiation, and Freeze-Thaw Survival of Human Wharton's Jelly Mesenchymal Stem Cells from Early and Late Passages. Bioscience Research, Volume 15(1), pp. 392-401

Rizal, R., Widodo, W.S., Wibowo, S., Munshy, U.Z., 2019. Effect of Serial Passage on Growth Kinetics, Biological Properties, and Differentiation into Adipocytes of Human Wharton's Jelly-Derived Mesenchymal Stem Cells. Majalah Kedokteran Bandung, Volume 51(3), pp. 127-133

Shivakumar, S.B., Lee, H.J., Son, Y.B., Bharti, D., Ock, S.A., Lee, S.L., Kang, Y.H., Park, B.W., Rho, G.J., 2019. In vitro Differentiation of Single Donor Derived Human Dental Mesenchymal Stem Cells into Pancreatic $\beta$ Cell-like Cells. International Journal of Bioscience reports, Volume 39(5), pp. 1-14

Supriadi, C.P., Kartini, E., Honggowiranto, W., Basuki, K.T., 2017. Synthesis and Characterization of Carbon Material Obtained from Coconut Coir Dust by Hydrothermal and Pyrolytic Processes. International Journal of Technology, Volume 8(8), pp. 1470-1478

Todeschi, M.R., ElBackly, R., Capelli, C., Daga, A., Patrone, E., Introna, M., Cancedda, R., Mastrogiacomo, M., 2015. Transplanted Umbilical Cord Mesenchymal Stem Cells Modify the in Vivo Microenvironment Enhancing Angiogenesis and Leading to Bone Regeneration. International Journal of Stem Cells and Development, Volume 24(13), pp. 1570-1581

Ullah, I., Lee, R., Oh, K.B., Hwang, S., Kim, Y., Hur, T.Y., Ock, S.A., 2020. Transdifferentiation of $\alpha-1,3$-Galactosyltransferase Knockout Pig Bone Marrow Derived Mesenchymal Stem Cells into Pancreatic $\beta$-like Cells by Microenvironment Modulation. Asian-Australasian Journal of Animal Sciences, Volume 33(11), pp. 1837-1847 
Ullah, M., Liu, D.D., Thakor, A.S., 2019. Mesenchymal Stromal Cell Homing: Mechanisms and Strategies for Improvement. International Journal of Iscience, Volume 15, pp. 421-438

Utama, B.I., 2018. Isolation of Amniotic Fluid Mesenchymal Stem Cells (Af-Mscs) Obtained from Caesarean Sections. Andalas Obstetrics and Gynecology Journal, Volume 2(1), pp. $1-9$

Van Pham, P., Truong, N.C., Le, P.T.B., Tran, T.D.X., Vu, N.B., Bui, K.H.T., Phan, N.K., 2016. Isolation and Proliferation of Umbilical Cord Tissue Derived Mesenchymal Stem Cells for Clinical Applications. International Journal of Cell and Tissue Banking, Volume 17(2), pp. 289-302

Wagner, W., Feldmann Jr, R.E., Seckinger, A., Maurer, M.H., Wein, F., Blake, J., Krause, U., Kalenka, A., Burgers, H., Saffrich, R., Wuchter, P., 2006. The Heterogeneity of Human Mesenchymal Stem Cell Preparations-Evidence from Simultaneous Analysis of Proteomes and Transcriptomes. Experimental hematology, Volume 34(4), pp. 536-548

Wagner, W., Horn, P., Castoldi, M., Diehlmann, A., Bork, S., Saffrich, R., Benes, V., Blake, J., Pfister, S., Eckstein, V., Ho, A.D., 2008. Replicative Senescence of Mesenchymal Stem Cells: A Continuous and Organized Process. PloS one, Volume 3(5), pp. 1-12

Wang, Q., Yang, Q., Wang, Z., Tong, H., Ma, L., Zhang, Y., Shan, F., Meng, Y., Yuan, Z., 2016. Comparative Analysis of Human Mesenchymal Stem Cells from Fetal-Bone Marrow, Adipose Tissue, and Warton's Jelly as Sources of Cell Immunomodulatory Therapy. International Journal of Human Vaccines \& Immunotherapeutics, Volume 12(1), pp. 85-96

Widowati, W., Gunanegara, R.F., Rizal, R., Widodo, W.S., Amalia, A., Wibowo, S.H.B., Handono, K., Marlina, M., Lister, I.N.E., Chiuman, L., 2019. Comparative Analysis of Wharton's Jelly Mesenchymal Stem Cell (WJ-MSCs) Isolated using Explant and Enzymatic Methods. In: Journal of Physics: Conference Series (Volume 1374, No. 1, p. 012024). IOP Publishing

Wilson, L.D., Mahmud, S.T., 2015. The Adsorption Properties of Surface-Modified Mesoporous Silica Materials with ß-Cylodextrin. International Journal of Technology, Volume 6(4), pp. 533-545

Wolbank, S., Peterbauer, A., Fahrner, M., Hennerbichler, S., Van Griensven, M., Stadler, G., Redl, H., Gabriel, C., 2007. Dose-Dependent Immunomodulatory Effect of Human Stem Cells from Amniotic Membrane: A Comparison with Human Mesenchymal Stem Cells from Adipose Tissue. International Journal of Tissue engineering, Volume 13(6), pp. 1173-1183

Zajdel, A., Kałucka, M., Kokoszka-Mikołaj, E., Wilczok, A., 2017. Osteogenic Differentiation of Human Mesenchymal Stem Cells from Adipose Tissue and Wharton's Jelly of the Umbilical Cord. Acta Biochimica Polonica, Volume 64(2), pp. 365-369

Zakrzewski, W., Dobrzyński, M., Szymonowicz, M., Rybak, Z., 2019. Stem Cells: Past, Present, and Future. International Journal of Stem Cell Research \& Therapy, Volume 10(68), pp. $1-22$

Zhang, B., 2010. CD73: A Novel Target for Cancer Immunotherapy. Cancer Research, Volume 70(16), pp. 6407-6411 